\title{
The pseudo-Thellier palaeointensity method: new calibration and uncertainty estimates
}

\author{
Greig A. Paterson, ${ }^{1}$ David Heslop ${ }^{2}$ and Yongxin Pan ${ }^{1}$ \\ ${ }^{1}$ Key Laboratory of the Earth and Planetary Physics, Institute of Geology and Geophysics, Chinese Academy of Sciences, Beijing 100029, China. \\ E-mail: greig.paterson@mail.iggcas.ac.cn \\ ${ }^{2}$ Research School of Earth Sciences, Australian National University, Bldg. 142, Mills Rd., Acton, ACT 2601, Australia
}

Accepted 2016 September 16. Received 2016 September 13; in original form 2016 June 12

\begin{abstract}
SUMMAR Y
Non-heating palaeointensity methods are a vital tool to explore magnetic field strength variations recorded by thermally sensitive materials of both terrestrial and extraterrestrial origin. One such method is the calibrated pseudo-Thellier method in which a specimen's natural remanent magnetization is alternating field demagnetized and replaced with a laboratory induced anhysteretic remanent magnetization (as an analogue of a thermoremanent magnetization, TRM). Using a set of 56 volcanic specimens given laboratory TRMs in fields of $10-130 \mu \mathrm{T}$, we refine the calibration of the pseudo-Thellier method and better define the uncertainty associated with its palaeointensity estimates. Our new calibration, obtained from 32 selected specimens, resolves the issue of non-zero intercept, which is theoretically predicted, but not satisfied by any previous calibration. The range of individual specimen calibration factors, however, is relatively large, but consistent with the variability expected for SD magnetite. We explore a number of rock magnetic parameters in an attempt to identify selection thresholds for reducing the calibration scatter, but fail to find a suitable choice. We infer that our careful selection process, which incorporates more statistics then previous studies, may be largely screening out any strong rock magnetic dependence. Some subtle grain size or mineralogical dependencies, however, remain after selection, but cannot be discerned from the scatter expected for grain size variability of SD magnetite. As a consequence of the variability in the calibration factor, the uncertainty associated with pseudo-Thellier results is much larger than previously indicated. The scatter of the calibration is $\sim 25$ per cent of the mean value, which implies that, when combined with the scatter of results typically obtained from a single site, the uncertainty of averaged pseudo-Thellier results will always be $>25$ per cent. As such, pseudo-Thellier results should be complementary to, and cross-validated with results from other methods. Nevertheless, the pseudo-Thellier method remains a valuable tool for obtaining palaeointensity estimates from thermally sensitive terrestrial and extraterrestrial materials and with careful data selection and analysis can yield results that are accurate to within a factor of 4 or better.
\end{abstract}

Key words: Archaeomagnetism; Palaeointensity.

\section{INTRODUCTION}

The challenges associated with obtaining estimates of absolute palaeointensity have led to a wide range of innovative methods to help improve data quality and quantity. In particular, specimens that are highly susceptible to thermal alteration during laboratory heating (e.g. meteorites and other extraterrestrial materials) have driven an upsurge in non-heating methods (e.g. Gattacceca \& Rochette 2004; Muxworthy \& Heslop 2011). One such approach is the calibrated pseudo-Thellier method, which uses laboratory induced anhysteretic remanent magnetization (ARM) to avoid heat- ing (e.g. Garrick-Bethell et al. 2009; Yu 2010; de Groot et al. 2013; Lappe et al. 2013).

Although non-heating ARM based methods have been used for some time (Stephenson \& Collinson 1974), they have recently been gaining more attention in terrestrial applications (e.g. de Groot et al. 2014). The basic premise of the most recent variant of the pseudo-Thellier method (de Groot et al. 2013) is that a specimen's natural remanent magnetization (NRM) is progressively alternating field (AF) demagnetized, before a laboratory induced ARM is progressively imparted using the same AF steps. This ARM is subsequently AF demagnetized at the same AF levels. By analogy 
with the analysis of thermoremanent magnetization (TRM) based absolute palaeointensity methods, the NRM lost is plotted against ARM gained to form a pseudo-Arai plot (cf. Nagata et al. 1963). The pseudo-Arai slope $\left(b_{\mathrm{PA}}\right)$ represents a measure of the relative palaeointensity (when compared with other specimens with similar rock magnetic properties), such that

$b_{\mathrm{PA}}=\frac{\mathrm{NRM} \text { lost }}{\text { ARM gained }}$.

Numerous authors have explored absolute calibrations of the pseudo-Thellier method, particularly in respect to extraterrestrial materials (e.g. Yu et al. 2003; Yu 2010; Lappe et al. 2013), but many of these studies only explore the demagnetization of ARM and not its acquisition. Most recently, de Groot et al. (2013) explored the calibration of the pseudo-Thellier method and its application to lava flows and utilized ARM acquisition characteristics to provide a means of screening out non-ideal factors (discussed further in later sections). Hereafter, in this work we use the term pseudo-Thellier to refer the calibrated pseudo-Thellier method used to obtain absolute palaeointensity estimates.

An absolute palaeointensity $\left(B_{\text {Anc }}\right.$ ) can be obtained by the use of an appropriate calibration factor $(c)$ using:

$B_{\mathrm{Anc}}=\left|b_{\mathrm{PA}}\right| \frac{B_{\mathrm{ARM}}}{c}$

where $B_{\mathrm{ARM}}$ is the DC bias field during ARM acquisition. de Groot et al. (2013) measured pseudo-Thellier data from historic lava flows from Hawaii and compared the pseudo-Arai slopes to the known field, but using a fixed ARM bias field of $40 \mu \mathrm{T}$. The above relation can then be expressed as

$B_{\mathrm{Anc}}=\frac{\left|b_{\mathrm{PA}}\right|}{c_{40}}$,

where $c_{40}$ is the calibration in $40 \mu \mathrm{T} \mathrm{DC}$ field $\left(c=c_{40} \times B_{\mathrm{ARM}}\right)$. Over a narrow field range (34.7-37.7 $\mu \mathrm{T})$, de Groot et al. (2013) introduced an intercept term and obtained the following calibration relationship: $B_{\mathrm{Anc}}(\mu \mathrm{T})=7.371 \times\left|b_{\mathrm{PA}}\right|+14.661\left(c_{40}=0.1357\right)$. In this work, we also use an ARM bias field of $40 \mu \mathrm{T}$ and primarily focus on determining the $c_{40}$ calibration factor.

Subsequent work by de Groot et al. (2015) and de Groot et al. (2016) compared pseudo-Arai slopes with palaeointensities obtained from thermal based methods (e.g. Tauxe \& Staudigel 2004; Dekkers \& Böhnel 2006) in an attempt to improve the calibration. Although these improvements do not change the calibration notably, we view the original calibration as the most appropriate. This is because in all subsequent work, the fields that the pseudo-Arai slopes are compared with are unknown, thus this is not strictly calibration of the pseudo-Thellier method, but rather a measure of the consistency with results obtained from different methods.

Despite the attempts to improve the calibration, all previously proposed relationships have a non-zero intercept of $\sim 14 \mu \mathrm{T}$. Theoretically, however, it is expected that such a calibration should have zero intercept and should be a simple scaling relationship (i.e. a specimen with zero NRM should have a pseudo-Arai slope of zero). To explain this, de Groot et al. (2013) suggest that the calibration is highly nonlinear in the low field range. Although acknowledged as being far from ideal, to-date, there is no satisfactory explanation of the physical significance of a non-zero intercept.

In this study, we report new pseudo-Thellier data obtained from a suite of 56 well characterized specimens imparted with laboratory induced TRMs. Using these results, we propose a new data selection process and a new calibration of the pseudo-Thellier method that resolves the non-zero intercept problem and provides a better estimate of the uncertainty associated with the calibration and pseudo-Thellier results.

\section{METHODS}

\subsection{Specimens and measurements}

A total of 56 specimens were used in this study ( $1 \mathrm{~cm}$ cores). Forty of the specimens were taken from studies of Paterson et al. (2010a) and Paterson et al. (2010b) and are from Mt. St. Helens, USA and Vesuvius, Italy. In addition, we use 16 unpublished basaltic specimens from the Emeishan large igneous province. Specimen names are grouped by locality. 'A' and ' $C$ ' specimens are from Emeishan, 'D' specimens are from Mt. St. Helens, and 'L' specimens are from Vesuvius.

Prior to measurement for this study, all specimens had undergone at least two full thermal palaeointensity experiments and multiple heatings to $700{ }^{\circ} \mathrm{C}$ to ensure thermal stability. In Supporting Information Fig. S1, we compare the hysteresis parameters from our thermally stabilized specimens to fresh sister specimens (Paterson et al. 2010b; and unpublished measurements of the Emeishan basalts). We find that although there is slight hardening of coercivity (a median increase of $\sim 15$ per cent) that results in lower $B_{\mathrm{cr}} / B_{\mathrm{c}}, M_{\mathrm{rs}} / M_{\mathrm{s}}$ is not affected by a systematic change. When compared to hysteresis data from unheated volcanic material (Paterson et al. 2010b; Muxworthy et al. 2011), our heated specimens are indistinguishable from the broad range behaviour exhibited by natural specimens, which indicates that our specimens are suitable for comparison with unheated natural materials.

To produce NRMs, the specimens were given full TRMs (imparted at $700^{\circ} \mathrm{C}$ ) in fields of $10,50,90$ and $130 \mu \mathrm{T}$ using a Magnetic Measurements MMTD-SC furnace. For specimens L5 and $\mathrm{L} 9$, no $50 \mu \mathrm{T}$ data are available. All remanence measurements were performed using a $2 \mathrm{G}$ Enterprises 760 cryogenic magnetometer. AF demagnetization (along three axes: $X$-, $Y$-, then $Z$-) was carried out in 14 steps $(2.5,7.5,10,15,20,25,30,35,40,50,60,80$, 100 and $120 \mathrm{mT}$ ) using the inline static AF demagnetizer of the magnetometer (model 2G600). This is long-core AF system where the AF amplitude spatially decays. The AF system operates at a frequency of $\sim 200 \mathrm{~Hz}$ ( $X$ - and $Y$-axes) or $\sim 150 \mathrm{~Hz}(Z$-axis) and a translation speed of $25 \mathrm{~cm} \mathrm{~s}^{-1}$ was used. ARMs were progressively imparted using the magnetometer's inline coil (model 625 ARM) with a bias field of $40 \mu \mathrm{T}$ using the peak AFs given above. The ARMs were subsequently AF demagnetized at the same AF steps. For each NRM field, the measurements of ARM acquisition and demagnetization were repeated. Both NRM and ARM were acquired along the specimens' $Z$-axis and during ARM acquisition the AF was also along the $Z$-axis. We note that in our system no notable currents are induced in the ARM bias field due to the AF signal.

Magnetic hysteresis and isothermal remanent magnetization (IRM) acquisition were measured on a Princeton Measurements Corporation vibrating sample magnetometer (model 3900) up to a peak field of 1.4 T. Hysteresis data were processed following the recommendations of Jackson \& Solheid (2010) and where necessary the approach to saturation method of Fabian (2006) was applied. Saturation IRMs (SIRMs) were determined from the hysteresis data after correction for dia-/paramagnetic contributions and approach to saturation. All rock magnetic measurements were performed on exactly the same specimens as the pseudo-Thellier experiments. 
Table 1. Summary of employed selection statistics.

\begin{tabular}{lccl}
\hline Statistic & Threshold & Applied Plot & \multicolumn{1}{c}{ Reason } \\
\hline$n$ & $\geq 6$ & All & Sufficient data points should be used for fitting \\
$f$ & $\geq 0.45$ & Pseudo-Arai & Sufficient NRM should be used \\
$\beta$ & $\leq 0.1$ & Pseudo-Arai & Pseudo-Arai fit should not be scattered \\
$R^{2}$ corr & $\geq 0.995$ & All & All plots should be linear \\
$\left|\vec{k}^{\prime}\right|$ & $\leq 0.2$ & All & All plots should be linear \\
$f_{\text {Resid }}$ & $<0.15$ & Demag-Demag & To ensure NRM-ARM demag plot trends towards to origin \\
$b_{\text {AA }}$ & $0.85 \leq\left|b_{\text {AA }}\right| \leq 1.15$ & ARM-ARM & ARM-ARM plot should have an absolute slope of 1 \\
\hline
\end{tabular}

\subsection{Data analysis and selection}

As will be discussed below, our specimens have variable amounts of NRM remaining after demagnetization to $120 \mathrm{mT}$, which is due to the presence of a magnetically hard mineral (hematite). For our analyses, we therefore remove the residual magnetizations from all remanence data via vector subtraction. We note that this makes negligible difference to the final pseudo-Thellier calibration, but is necessary to obtain consistent characterization of the ARM acquisition and demagnetization data, which is relevant when considering rock magnetic selection (discussed in Section 4.3). For example, specimen $\mathrm{C} 2$, which is a basaltic lava, has residual NRMs of 4-7 per cent after AF demagnetization at $120 \mathrm{mT}$. Before subtracting the residual NRM from the ARM demagnetization, the ARM median destruction fields (MDFs) for C2 are 28.0, 32.5, 37.6 and $45.4 \mathrm{mT}$, for the 10, 50, 90 and $130 \mu \mathrm{T}$ fields, respectively. After subtracting the NRM residuals the ARM MDFs are 26.5, 27.2, 27.1 and $27.3 \mathrm{mT}$, respectively.

To ensure reliable estimates of pseudo-Arai plot slope, de Groot et al. (2013) recommend identifying a linear segment on the plot of ARM left versus NRM left (what we refer to as the demag-demag plot). This segment could then be used for analysing the pseudo-Arai plot. Here we introduce additional selection requirements, which are all based on desirable or theoretically expected behaviour. These are summarized in Table 1 and we follow the Standard Paleointensity Definition (SPD) terminology (Paterson et al. 2014). First, to ensure that sufficient data points and NRM fraction are used to make an estimate of the pseudo-Arai slope we require $n \geq 6$ and $f \geq 0.45$. By analogy with traditional double heating Arai plot analysis, we also require that $\beta \leq 0.1$.

Following de Groot et al. (2013), we note that in the ideal case, over the selected AF interval, the demag-demag plot, the pseudoArai plot, and the ARM left versus ARM gained plot (what we refer to as the ARM-ARM plot), should all be linear. The expectation of linearity comes from Thellier's law of reciprocity (Thellier \& Thellier 1959). This fundamental assumption of all palaeointensity studies, states that the blocking spectrum activated by the NRM and by the laboratory remanence should be identical. This assumption is irrespective of the mineralogy carrying the remanence or whether it is blocking temperature or coercivity spectra that are activated. Violation of this requirement would result in nonlinear plots when different remanences are compared with each other and therefore linearity is a simple test that this basic assumption holds true. Therefore, when making fits to the pseudo-Arai plots we consider the linearity of all three plot types. We quantify linearity using the curvature of the fitted segment $\left(\left|\vec{k}^{\prime}\right|\right)$ (Paterson 2011; Paterson et al. $2015)$ as well as the square of the Pearson linear correlation coefficient $\left(R_{\text {corr }}^{2}\right)$. A segment is chosen if $R_{\text {corr }}^{2} \geq 0.995$ and $\left|\vec{k}^{\prime}\right| \leq 0.2$. These two linearity requirements are applied to all three analysis plots (i.e. the demag-demag, pseudo-Arai, and ARM-ARM plots). de Groot et al. (2013) also note that the best-fit segment on the demag-demag plot should trend towards the origin if the two remanences are being properly demagnetized. To quantitatively assess this, here we introduce $f_{\text {Resid }}$ as measure of the residual fraction. This is an analogy of the NRM fraction (f) of Coe et al. (1978) and is given by

$f_{\text {Resid }}=\frac{\left|Y_{\text {Int. }}\right|}{\Delta y^{\prime}}$,

where $Y_{\text {Int. }}$ is the $y$-intercept on the demag-demag plot and $\Delta y^{\prime}$ is the change in the ARM lost over the selected segment (see SPD; Paterson et al. 2014). This statistic biases against fits with large intercepts, or fits where only a small amount of ARM is lost. We only select fits with $f_{\text {Resid }} \leq 0.15$.

Finally, we note that, not only should the ARM-ARM plot be linear, but, in the absence of non-ideal factors, this plot should have a slope of -1 . That is, for a selected AF range, ARM lost should be identical to the ARM gained. Violation of this is an indication of non-reciprocal ARM, which is a prerequisite of ARM based palaeointensity methods (Yu et al. 2002). We quantify this by requiring that the ARM-ARM slope $\left(b_{\mathrm{AA}}\right)$ should be in the range $0.85 \leq\left|b_{\mathrm{AA}}\right| \leq 1.15$ (Table 1 ). The slope is calculated using stand major axis regression (see SPD; Paterson et al. 2014).

To account for rock magnetic variability and to improve the consistency of the calibration, de Groot et al. (2013) proposed $B_{1 / 2} \mathrm{ARM}$, which is half the field required to impart the saturation ARM, as means of rock magnetic screening. They recommended that $B_{1 / 2} \mathrm{ARM}$ should lie between 23-63 mT. We begin by first exploring the calibration without rock magnetic consideration (Section 3.2) and discuss rock magnetic factors in more detail in Section 4.3.

\section{RESULTS}

\subsection{Remanence and demagnetization behaviour}

For all 56 specimens, TRM acquisition is linear with applied field $(R \geq 0.992, p \leq 0.035)$. Therefore, over the field range explored here $(10-130 \mu \mathrm{T})$, nonlinear TRM acquisition need not be considered. Similarly, since all remanences are acquired along the same axis, anisotropy does not need to be considered.

de Groot et al. (2013) were able to demagnetize their specimens up to $300 \mathrm{mT}$, but we were only able to demagnetize our specimens to $120 \mathrm{mT}$. As a result, for our specimens variable amounts of NRM remain after demagnetization (5-40 per cent). Eleven specimens ( $\sim 20$ per cent of all specimens) have mean residual NRMs $>15$ per cent, indicating magnetically hard minerals. This is most likely hematite, which is known to be present in some specimens before thermal stabilization (Paterson et al. 2010a,b), but may also form during the stabilization process. We note that the median 
(a)

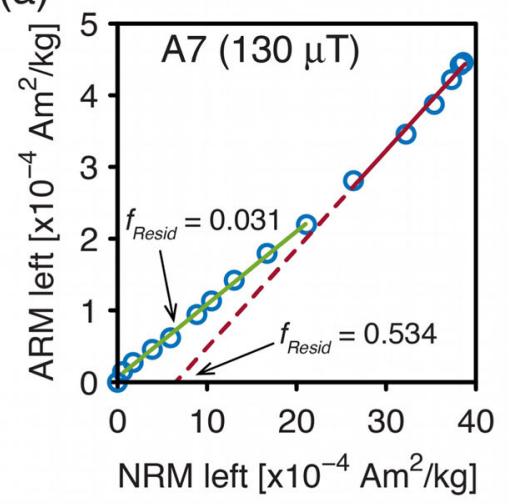

(d)

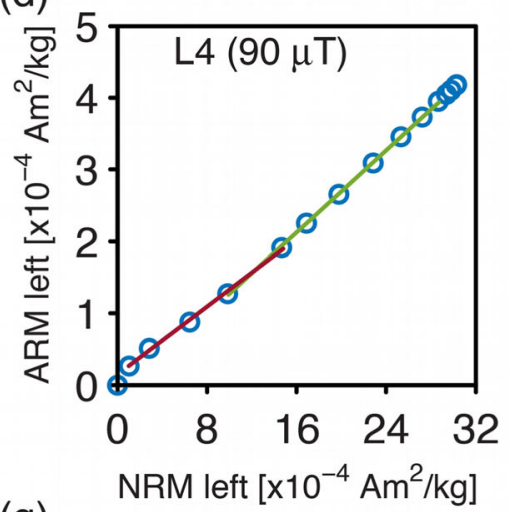

(g)

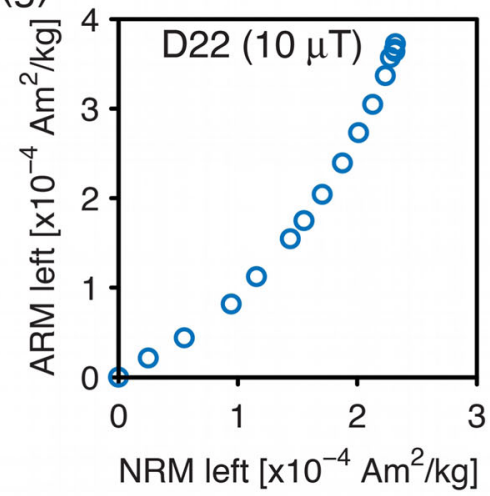

(b)

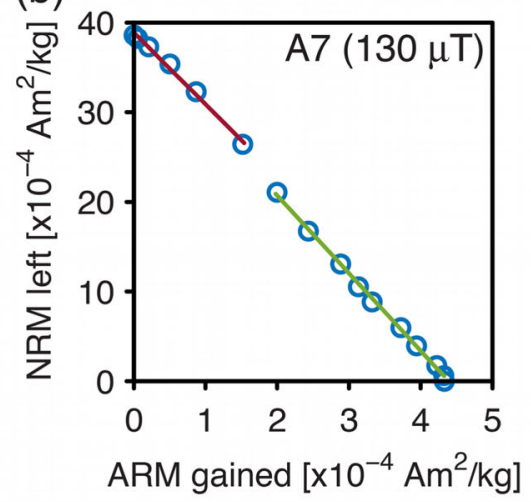

(e)

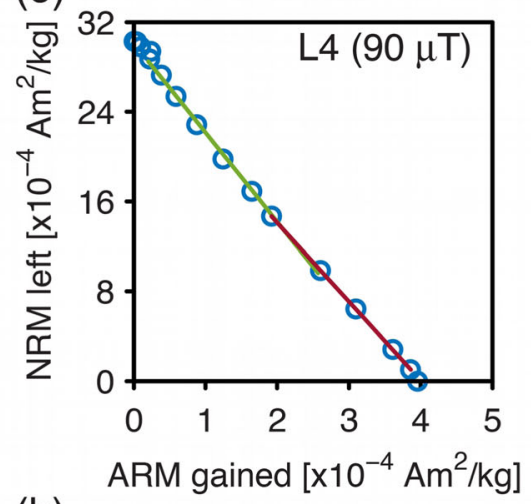

(h)

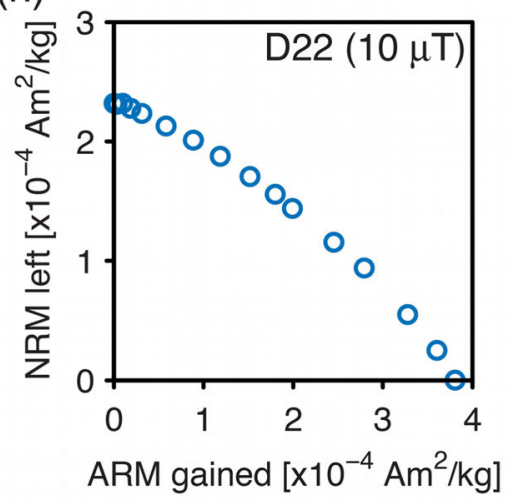

(c)

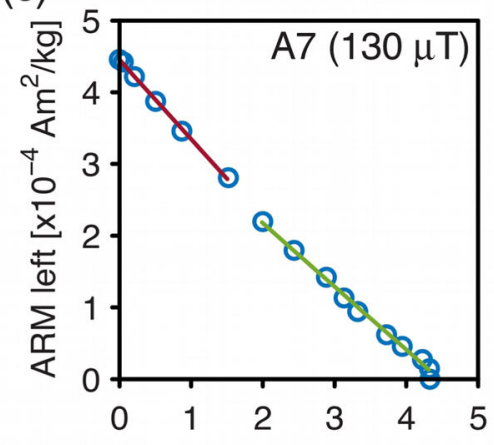

ARM gained $\left[\times 10^{-4} \mathrm{Am}^{2} / \mathrm{kg}\right]$

(f)

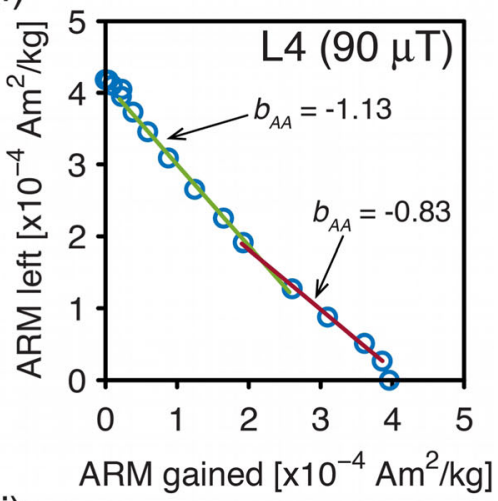

(i)

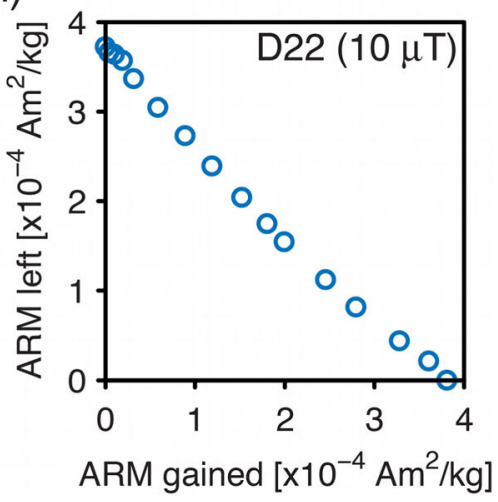

Figure 1. Example demag-demag (a, d, g), pseudo-Arai (b, e, h) and ARM-ARM pots (c, f, i) that illustrate a range of remanence behaviour. Green lines correspond to example fits that pass the applied selection criteria (Table 1) and red lines are example fits that fail.

residual NRM is $\sim 12$ per cent, which means that half of our specimens have residual NRMs that would be broadly consistent with magnetically soft minerals such as magnetite and maghemite. After subtraction of residual NRM, reproducibility of the total ARM is within $<10$ per cent of the mean (generally $<6$ per cent), which confirms the thermal stability of the specimens.

Example demag-demag, pseudo-Arai, and ARM-ARM plots are shown in Fig. 1. These illustrate the range of behaviour that we observe and we highlight examples of fits that pass and fail selection. For the $130 \mu \mathrm{T}$ experiment for specimen A7 (Figs 1a-c), we find that although the low coercivity range yields linear fits, they fail to trend to the origin on the demag-demag plot (Fig. 1a). The higher coercivity ranges, however, pass selection. Specimen L4 $(90 \mu \mathrm{T}$; Figs 1d-f) illustrates a case where the high coercivity range is linear and trends close to the origin of the demag-demag plot $\left(f_{\text {Resid }}\right.$ $\sim 0.06$ ), but where the slope of the ARM-ARM plot is -0.83 and not near the expected value of -1 (Fig. 1f). In this case, the lower coercivity ranges tend to pass our selection. Lastly, specimen D22 $(10 \mu \mathrm{T}$; Figs $1 \mathrm{~g}-\mathrm{h})$ is an example of where all plots are highly nonlinear and no fit can be found that passes our selection requirements. This indicates that the ARM acquisition and demagnetization and NRM demagnetization are not activating the same coercivity spectra, violating the assumption of reciprocity.

\subsection{Pseudo-Thellier calibration}

For most specimens, we identify multiple AF ranges that pass our selection criteria (Table 1). We therefore analyse all possible fits. Of the 222 experiments we performed, 136 yield at least one fit that passes selection. This represents 46 of 56 specimens. To determine the calibration of each specimen, we accept only specimens that yield acceptable results from at least three different TRM fields. 
(a)

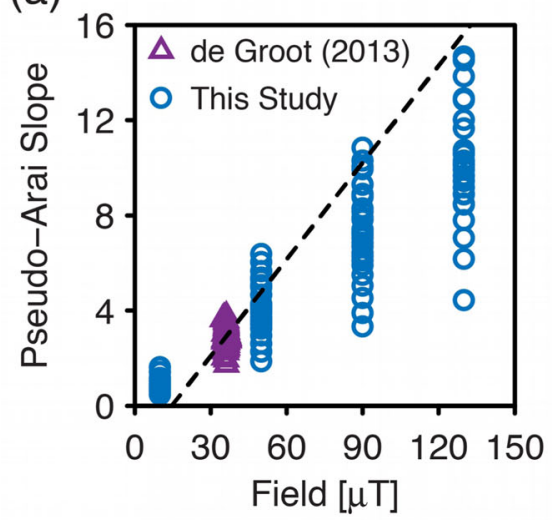

(d)

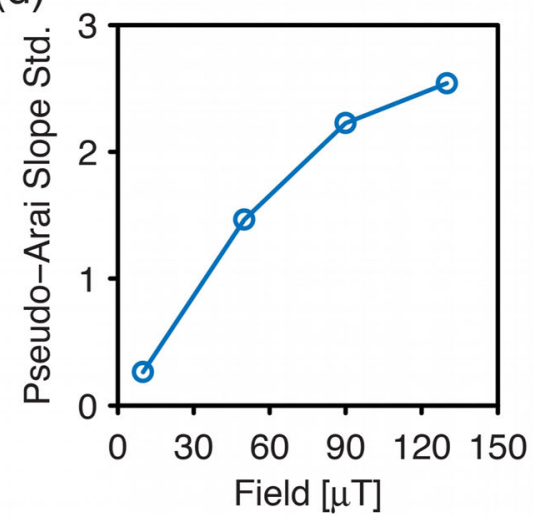

(b)

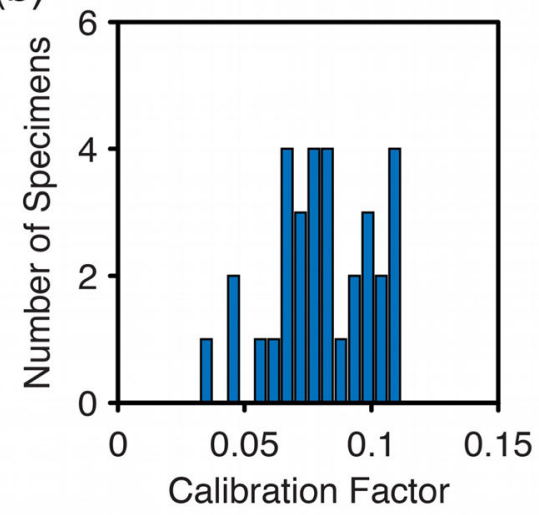

(e)

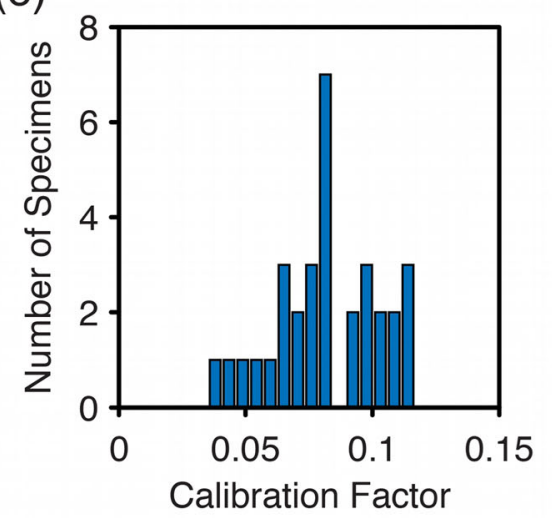

(c)

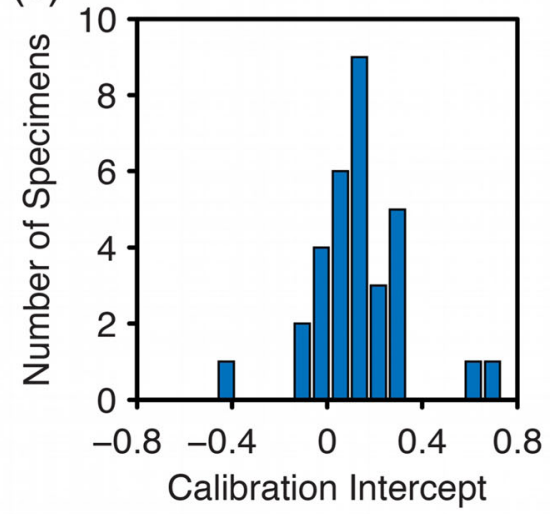

(f)

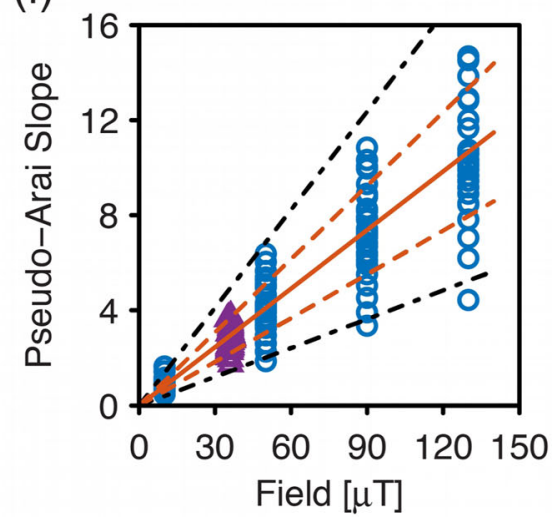

Figure 2. (a) Accepted mean pseudo-Arai slopes as a function of the NRM field. Blue circles are our new data, the purple triangles are from de Groot et al. (2013) and the dashed line is the calibration of de Groot et al. (2013). (b, c) Histograms of the calibration factor and intercept, respectively, from a non-anchored robust linear fit to data from each individual specimen. (d) The standard deviation of the pseudo-Arai plot slopes as a function of the NRM field. (e) Histogram of the calibration factors from an anchored robust linear fit to data from each individual specimen. (f) The accepted pseudo-Arai slopes as a function of the NRM field, alongside our new calibration. The solid orange line represents our new mean calibration and the orange dashed lines denote the one standard deviation envelope. The black dash-dot lines are the expected calibrations from $30 \mathrm{~nm}$ (lower) and 57 nm (upper) magnetite (Dunlop \& West 1969). Other symbols are as in part (a).

This leaves a total of 32 out of 56 specimens that yield a calibration estimate, which represents 117 out of 222 experiments.

Given that multiple fits for each experiment are possible, we take the average of all pseudo-Arai slope estimates for each experiment. For example, for the $130 \mu \mathrm{T}$ experiment for specimen L2 (Figs 1a-c), 38 possible fits pass our selection criteria with an average of $9.17 \pm 0.23$ (all uncertainties are given as \pm one standard deviation, unless stated otherwise). This average value is taken to be our pseudo-Arai slope estimate for the $130 \mu \mathrm{T}$ experiment for specimen L2. The effect in choosing different possible best-fit segments is found to be negligible and is discussed in Section 4.4. The accepted mean slopes and their standard deviations are given in Supporting Information Table S1.

All 117 accepted results are shown in Fig. 2(a) along with the accepted Hawaiian data and pseudo-Thellier calibration from de Groot et al. (2013). Although the Hawaiian data are consistent with our new data, the original calibration of de Groot et al. (2013), which differs only slightly from later modifications, systematically differs from our observations.

For each specimen, we perform robust linear fitting with an intercept term and histograms of the slope and intercepts are shown in Figs 2(b) and (c), respectively. The mean slope (the calibration factor $c_{40}$ ) and intercept are 0.0806 and 0.1349 , respectively. The mean intercept corresponds to a zero pseudo-Arai plot slope field estimate of $-1.7 \mu \mathrm{T}$. This mean field intercept is almost an order of magnitude less than previous calibrations, which yielded values of $\sim 14 \mu \mathrm{T}$ (de Groot et al. 2013, 2015, 2016). The histogram of the intercepts has a clustering of values close to zero (Fig. 2c), but with a tendency to be slightly larger than zero. We also robustly fit each specimen with a linear model without an intercept term (i.e. anchored to the origin). An F-test comparison of variance between the two models reveals that for 31 out of the 32 specimens the simpler model without an intercept term yields a statistically better fit to the data at the 5 per cent significance level. The theoretical expectation of zero-intercept and the fact that it is statistically supported by the data strongly suggest that the calibration of the pseudo-Thellier method should be a simple scaling rule without an intercept term (as given in eqs 3 and 4). We therefore prefer to adopt the calibration factors obtained from a robust linear fit without an intercept term.

The histogram of calibration factors is shown in Fig. 2(e). The values range from 0.0353 to 0.1167 , with a mean of $0.0820 \pm 0.0207$. The mean calibration value and the standard deviation interval are plotted in Fig. 2(f). This new calibration is consistent with the Hawaiian data used by de Groot et al. (2013) to develop their initial calibration (discussed further in Section 4.4). We note that using the same selected specimens and pseudo-Arai plot segments, but not removing the residual NRMs, yields a mean value of $0.0819 \pm 0.0205$, 


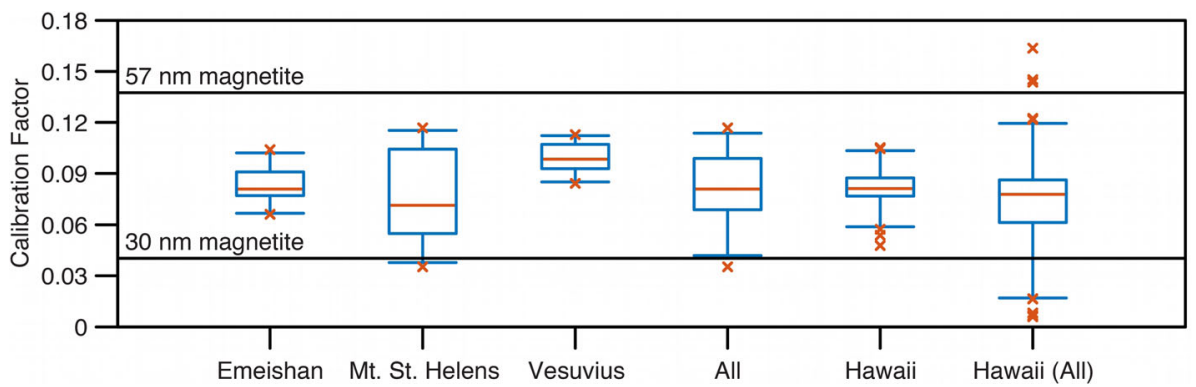

Figure 3. Box-whisker plots of our accepted specimen calibration factors for the Emeishan basalts (specimen groups A and C), Mt. St. Helens (group D), Vesuvius (group L), and all groups combined. The Hawaiian data are from de Groot et al. (2013) and are their selected ('Hawaii') and unselected ('Hawaii (All)') data. The $30 \mathrm{~nm}$ and $57 \mathrm{~nm}$ solid lines are the expected calibrations for SD magnetite (Dunlop \& West 1969). In this plot, the boxes denote the interquartile ranges, the whiskers the 95 per cent ranges and the orange lines are the median values. The orange crosses represent values that lie outside the 95 per cent ranges.

Table 2. Descriptive statistics of the calibration factors from the different localities. $N$ is the total number of specimens and $n$ is the number of specimens that passed selection. The Hawaii data are from de Groot et al. (2013).

\begin{tabular}{lccccccc}
\hline Location & Group & $n / N$ & Min. & Max. & Calibration factor \\
Median & Mean & Std. Dev. \\
\hline Emeishan LIP, China & A, C & $16 / 16$ & 0.0662 & 0.1040 & 0.0807 & 0.0827 & 0.0108 \\
Mt. St. Helens, USA & $\mathrm{D}$ & $13 / 32$ & 0.0353 & 0.1167 & 0.0692 & 0.0771 & 0.0287 \\
Vesuvius, Italy & $\mathrm{L}$ & $3 / 8$ & 0.0841 & 0.1127 & 0.1013 & 0.0994 & 0.0144 \\
All & $\mathrm{A}, \mathrm{C}, \mathrm{D}, \mathrm{L}$ & $32 / 56$ & 0.0353 & 0.1167 & 0.0807 & 0.0820 & 0.0207 \\
Hawaii & Selected & $93 / 197$ & 0.0479 & 0.1052 & 0.0812 & 0.0811 & 0.0107 \\
Hawaii & All & $197 / 197$ & 0.0059 & 0.1637 & 0.0776 & 0.0733 & 0.0242 \\
\hline
\end{tabular}

which is consistent with the value after residual NRMs are subtracted.

\section{DISCUSSION}

\subsection{Locality variability}

Taken en masse, our new calibration data and that of de Groot et al. (2013) are consistent, but they come from four distinct localities. Fig. 3 is a box-whisker plot of the specimen calibration factors broken down by locality and some key values are summarized in Table 2. All three of our localities yield consistent results, but the scatter of the calibration factors from Mt. St. Helens is higher than the other locales. This is likely related to a wider range of lithologies and hence magnetic properties from this locality. Mt. St. Helens has the lowest mean/median values, followed by Emeishan, then Vesuvius (Table 2). The box-whisker plot for all of the selected specimens has a consistent overlap with all three localities, which suggests that no locality is distinctly different from any other.

Fig. 3 and Table 2 also summarize the Hawaiian data from de Groot et al. (2013). Here, we simply estimate the individual specimen calibration factors as the pseudo-Arai slope divided by the known ambient field during NRM acquisition. The selected data of de Groot et al. (2013) are consistent with our combined data as well as the Emeishan and Mt. St. Helens data, but have slightly lower calibration factors than those from our Vesuvius specimens. The unselected data, however, exhibit a much wider range of variability that is consistent with all three of our individual localities and consistent with our pooled data. Slight differences between our data and that of de Groot et al. (2013) are therefore likely due to different data selection processes.

We also note that the data from de Groot et al. (2013) were measured at the palaeomagnetic laboratory in Utrecht using the AF and ARM systems attached to their robotized $2 \mathrm{G}$ magnetometer (Mullender et al. 2016). Their AF system operates at a frequency of $\sim 200 \mathrm{~Hz}$ and AF demagnetization was performed using a translation speed of $2 \mathrm{~cm} \mathrm{~s}^{-1}$, while ARM was acquired holding the specimen static as the fields were ramped up and down (de Groot, private communication, 2016). Despite notable differences in the experimental setup, our results are consistent (e.g. Figs 2, 3 and 7), which suggests that AF and ARM decay dependences may not be significant for these specimens. Alternatively, the general scatter of results may hide or be the result of decay rate dependences and future work should investigate this further.

\subsection{Inherent variability of $\boldsymbol{k}_{\mathrm{TRM}} / \boldsymbol{k}_{\mathrm{ARM}}$ : grain size effects}

After selection our calibration factors remain scattered; the standard deviation is $\sim 25$ per cent of the mean. It has long been recognized that the susceptibility of both TRM and ARM ( $k_{\mathrm{TARM}}$ and $k_{\mathrm{ARM}}$, respectively) depend on grain size, but $k_{\mathrm{ARM}}$ has a much stronger dependence (e.g. Dunlop \& West 1969; Levi \& Merrill 1976; Yu et al. 2003). As a result, the ratio of $k_{\mathrm{TARM}}$ to $k_{\mathrm{ARM}}$, which is essentially the reciprocal of the calibration factor, is strongly grain size dependent. Available data from SD magnetite $(\leq 65 \mathrm{~nm})$ indicate that the ratio of TRM to ARM ranges from $\sim 1.6$ to $\sim 5.5$ ( 6 data from Dunlop \& West 1969; Dunlop et al. 1975; Levi \& Merrill 1976; Yu et al. 2003). Assuming a DC bias field of $40 \mu \mathrm{T}$ during ARM acquisition, pseudo-Thellier $c_{40}$ calibration factors can be estimated for these specimens. The estimated calibration factors range from 0.0404 to 0.1374 with a mean of $0.0956 \pm 0.0325$, which is slightly larger than our estimate $(0.0820)$. The maximum and minimum calibrations factors, which come from the 30 and $57 \mathrm{~nm}$ specimens of Dunlop \& West (1969), respectively, are plotted in Figs 2(f) and 3. The range defined by these specimens encompasses our data well, suggesting that our observed variability is consistent with, or at least 

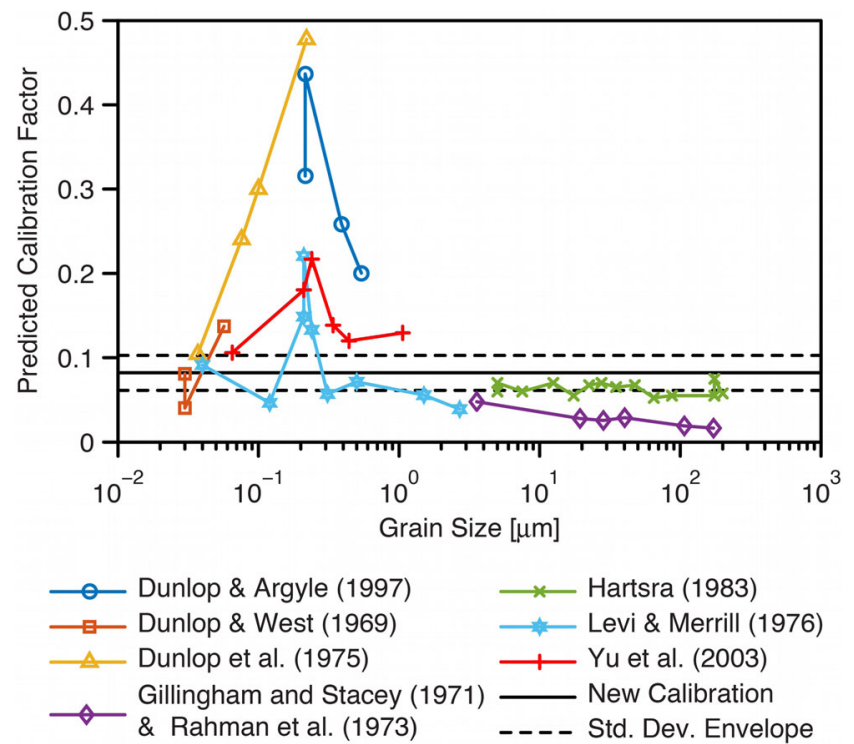

Figure 4. Predicted pseudo-Thellier calibration factors from sized magnetite specimens alongside our new calibration $(0.0820 \pm 0.0207)$ from volcanic materials. The predicted calibration factors are based on the reported values of the susceptibility of TRM and ARM and are determined for an ARM bias field of $40 \mu \mathrm{T}$.

indistinguishable from that expected for SD magnetite. Similarly, these bounds also encompass all of the Hawaiian data selected by de Groot et al. (2013) and much of their unselected results (Fig. 3).

In Fig. 4, we plot estimated calibration factors from available sized magnetite data (Dunlop \& West 1969; Gillingham \& Stacey 1971; Rahman et al. 1973; Dunlop et al. 1975; Levi \& Merrill 1976; Hartstra 1983; Dunlop \& Argyle 1997; Yu et al. 2003). This illustrates a sharp spike in the calibration factors in the pseudosingle domain (PSD) grain size range. It also illustrates, however, that the calibration factors that we observed are also consistent with some large PSD to small multidomain (MD) magnetite grain sizes (on the order of 0.3 to $\sim 3 \mu \mathrm{m}$ ), which would yield calibration factors of $\sim 0.0391$ to $\sim 0.1385$ (Levi \& Merrill 1976; Yu et al. 2003). Larger grain sizes are likely to yield low values of $\leq 0.075$ (Gillingham and Stacey; Rahman et al. 1973; Hartstra 1983) and may contribute to some of our lower estimates. Our selection process, which is discussed further below, is likely biasing against larger grain sizes, where the violation of reciprocity will be detected by our plot linearity criteria (e.g. Yu et al. 2003).

\subsection{Rock magnetic correlations and screening}

Given the abovementioned sensitivity of ARM to grain size it is desirable to attempt to restrict the range of specimens suitable for use with the pseudo-Thellier method. For this reason, de Groot et al. (2013) proposed the use of $B_{1 / 2} \mathrm{ARM}$ as a means of rock magnetic screening $\left(B_{1 / 2}\right.$ ARM is the field required to impart half of the saturation ARM). It should be noted that since our ARMs are not fully saturated some of our ARM quantifications might be underestimates. We therefore specifically note that these are the values for ARM acquired up to $120 \mathrm{mT}$ and are denoted as $\mathrm{ARM}_{120} \mathrm{MDF}$ and $B_{1 / 2}$ ARM 120 . We also use a high-field equivalent to $B_{1 / 2}$ ARM,$B_{1 / 2}$ SIRM which is the field required to impart half the SIRM. We calculate $B 1_{1 / 2}$ SIRM by normalizing the IRM acquisition curves by the SIRM obtained from the hysteresis measurements after correction for approach to saturation.
We first consider various rock magnetic parameters and the calibration factors without applying our new selection process. For each experiment, we take the mean of all possible pseudo-Arai plot fits with $n \geq 4$ and perform a robust linear regression on each specimen to determine the unselected calibration. We find that the low-field parameters (ARM ${ }_{120} \mathrm{MDF}, B_{1 / 2} \mathrm{ARM} 120$, and residual NRM) have no significant correlation (at the 5 per cent significance level) with the unselected calibration factors (Figs 5a-c). However, high-field parameters (i.e. squareness, coercivity, and $B_{1 / 2}$ SIRM) are strongly and significantly correlated with the unselected specimen calibrations (Figs $5 \mathrm{~d}-\mathrm{f}$ ). This suggests that the high-field measurements, which should be dominated by highly magnetic minerals (e.g. magnetite and maghemite), are picking up domain state (grain size and/or magnetic interaction) variations in these minerals. The highfield correlations are all positive (i.e. large values correspond to larger calibration factors). The more MD-like specimens (i.e. low squareness and coercivity) tend to yield lower calibration factors (Figs $5 \mathrm{~d}-\mathrm{f}$ ), which is consistent with the values expected from large PSD to MD magnetite (Fig. 4).

In Fig. 6, we compare our accepted specimen calibration factors with the various rock magnetic parameters (the data for the selected specimens are reported in Supporting Information Table S2). We find that the low-field parameters $\left(\mathrm{ARM}_{120} \mathrm{MDF}, B_{1 / 2} \mathrm{ARM} 120\right.$, and residual NRM) have significant (5 per cent level) correlations with the calibrations factors, with higher values of the low-field parameters having lower calibration factors (Figs $6 \mathrm{a}-\mathrm{c}$ ). The residual NRM is also correlated with both $\mathrm{ARM}_{120} \operatorname{MDF}(R=0.498, p=0.004)$ and $B_{1 / 2}$ ARM $120(R=0.445, p=0.011)$, which suggests that these parameters may be sensitive to the effectiveness of NRM demagnetization. For the high-field parameters (Figs 6d-f), however, we find no significant correlation with the calibration factors.

After applying our selection criteria described in Section 2.2, we observe a reduction in the correlation between the calibration factors and high-field rock magnetic properties, which we attribute to our selection process. The pseudo-Thellier data from Yu et al. (2003) exhibit an increase in plot curvature with increasing grain size for both the pseudo-Arai and ARM-ARM plots (the increase for the ARM-ARM plots is most distinct; Supporting Information Table S3). This increase in nonlinearity with increasing grain size is analogous to curvature on a traditional Arai plot (e.g. Levi 1977) and is a consequence of different coercivity spectra being activated by the NRM and laboratory ARM acquisition processes (i.e. a violation of reciprocity). Therefore, by applying a curvature specific selection criterion (Paterson 2011) we should be more effective in discriminating against larger grain sizes, which supports the suggestion that our calibration factors are consistent with the expected range of values from SD magnetite.

The increase in the correlation between the calibration factors and low-field remanence characteristic (e.g. Figs 5a and 6a) may be related to subtle variations in magnetic mineralogy of these particular specimens. Hematite is known to be present in some specimens and has likely formed during the thermal stabilization process. Our screening against nonlinear remanence behaviour most likely removed the dominant effect of domain state variations in highly magnetic minerals and may have revealed a more subtle influence of mineralogy. However, given that our range of calibration factors is consistent with grain size variability of magnetite, we cannot fully exclude the possibility that this is still related to a domain state effect (e.g. grain size).

de Groot et al. (2013) found $B_{1 / 2}$ ARM to be a useful selector and Figs 6(a) and (b) suggest that both $\mathrm{ARM}_{120} \mathrm{MDF}$ and $B_{1 / 2} \mathrm{ARM} 120$ may help exclude some of the lower calibration factors we obtain. 
(a)

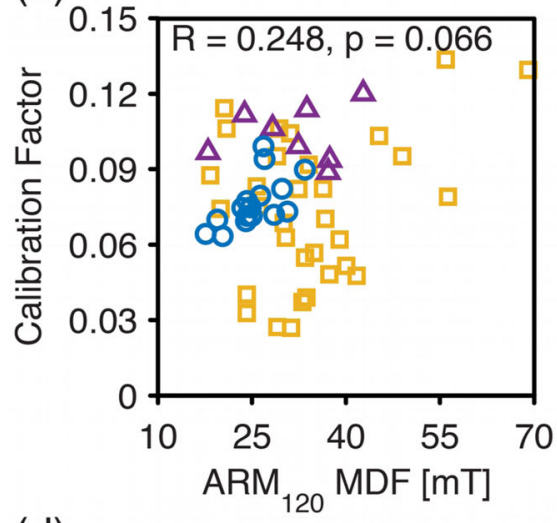

(d)

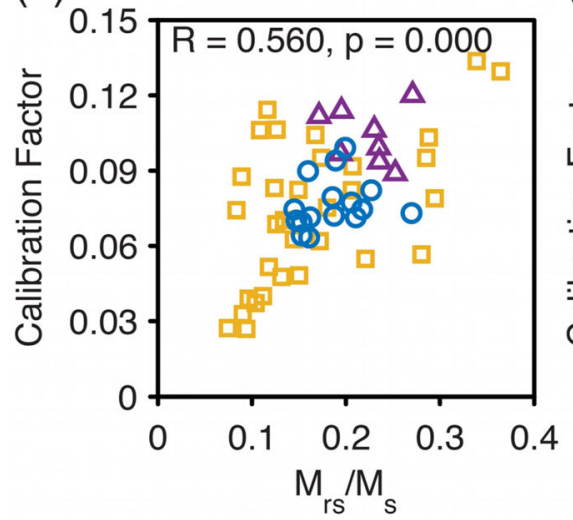

(b)

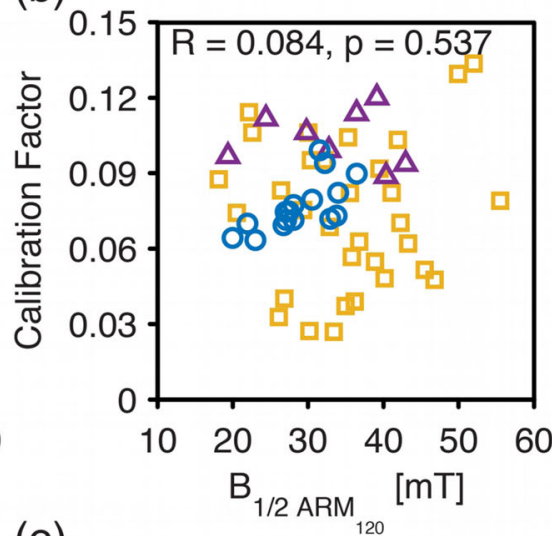

(e)

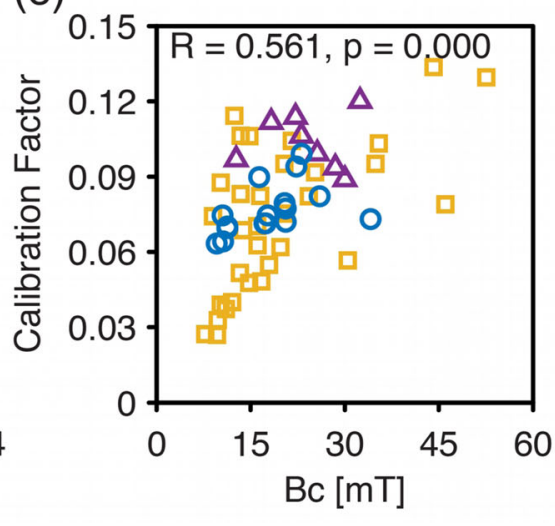

(c)

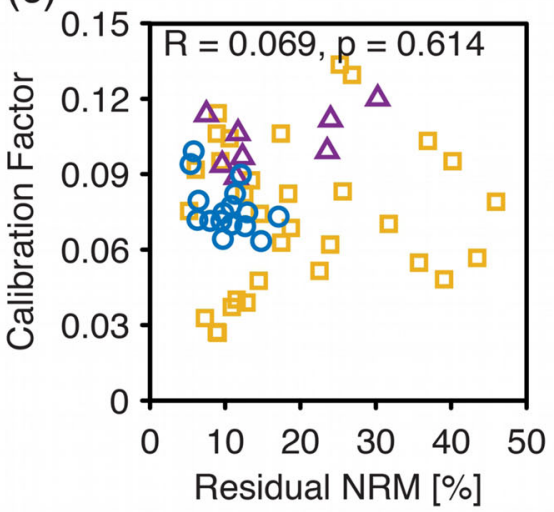

(f)

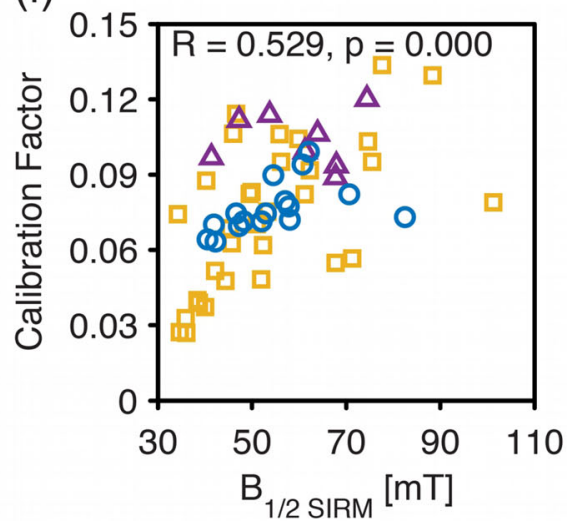

Figure 5. All specimen calibration factors as a function of (a) the $\mathrm{ARM}_{120} \mathrm{MDF}$, (b) $B_{1 / 2} \mathrm{ARM} 120$, (c) $B_{1 / 2} \mathrm{SIRM}$, (d) $M_{\mathrm{rs}} / M_{\mathrm{S}}$ (squareness), (e) coercivity ( $B_{\mathrm{c}}$ ), and (f) the mean residual NRM after demagnetization to $120 \mathrm{mT}$ (as a percentage of the original NRM). In all plots, the blue circles are the Emeishan specimens (groups A and C), the yellow squares are the Mt. St. Helens specimens (group D) and the purple triangles are the Vesuvius specimens (group L). $R$ and $p$ are the Pearson linear correlations and their significance, respectively.

Specifically, requiring $\mathrm{ARM}_{120} \mathrm{MDF} \leq 37.2 \mathrm{mT}$ or $B_{1 / 2 \mathrm{ARM} 120}$ $\leq 36.5 \mathrm{mT}$ yields calibrations of $0.0857 \pm 0.0178$ and $0.0891 \pm 0.0158$, respectively. This further rejects three or seven specimens, respectively. The validity of these calibrations is discussed below.

\subsection{Validity of the new calibration}

\subsubsection{Sensitivity to the choice of pseudo-Arai segment}

For each individual experiment (e.g. specimen D21 in $10 \mu \mathrm{T}$ ), multiple AF segments yield fits that pass our selection criteria (Table 1) and we simply estimate the calibration factor using the average pseudo-Arai slope from all acceptable fits for a particular experiment. To test the validity and robustness of this approach, we adopt a Monte Carlo resampling approach, whereby, for each specimen, we randomly select one acceptable fit for each field experiment and obtain a calibration factor. This is repeated for all 32 specimens and we can obtain an average calibration and its standard deviation. We repeat this process $10^{4}$ times to obtain distributions for both the mean calibration factor and standard deviation, which are shown in Figs 7(a) and (b), respectively.

The mean calibration factors range from 0.0810 to 0.0832 (min. to max.; 0.0818-0.0822 inter-quartile range) with a mean of $0.0820 \pm 0.0003$. The calibration uncertainties range from 0.0197 to 0.0217 (min. to max.; 0.0206-0.0209 inter-quartile range) with a mean of $0.0208 \pm 0.0003$. These values compare well with our final calibration of $0.0820 \pm 0.0207$ and confirm that, after data selection, our calibration it is robust against the choice of pseudo-Arai plot segment.

\subsubsection{An independent test}

de Groot et al. (2013) reported 197 pseudo-Thellier results from Hawaiian lava flows where the true field intensity was known. Of these, 93 passed their selection process $\left(23 \mathrm{mT} \leq B_{1 / 2} \mathrm{ARM} \leq\right.$ $63 \mathrm{mT}$ ) and were emplaced in fields of 34.7-37.7 $\mu \mathrm{T}$. Using both the selected and unselected pseudo-Arai plot slopes we determine new palaeointensity estimates and test two of our proposed calibrations (before and after selection using $\mathrm{ARM}_{120} \mathrm{MDF}$ ). For fair comparison, we normalize the estimates by the known fields and take the logarithm (referred to as the deviation, $c f$. Paterson et al. 2014). Kernel density plots of the deviations are shown in Figs 7(c) and (d): zero deviation corresponds to the correct result, negative and positive values correspond to under- and overestimates, respectively.

For the calibration before rock magnetic selection $(0.0820 \pm 0.0207)$, the deviations of the selected results peak close to zero and the deviation of mean values is -0.012 , which is an underestimate of $\sim 1.2$ per cent (Fig. 7c). Similarly, the deviations of the unselected results peak close to zero and the deviation of mean values is -0.113 (Fig. 7d). For the $\mathrm{ARM}_{120} \mathrm{MDF}$ 
(a)

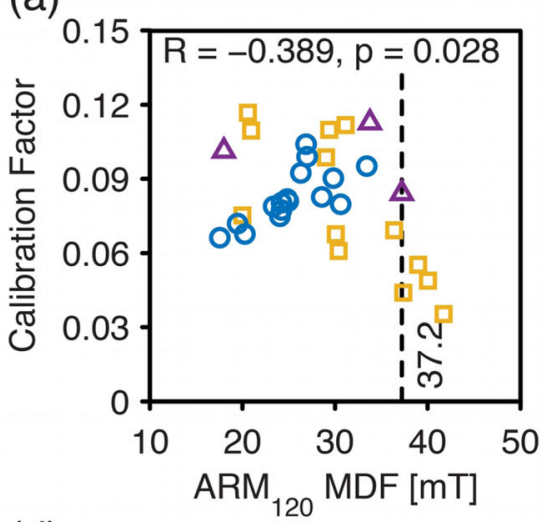

(d)

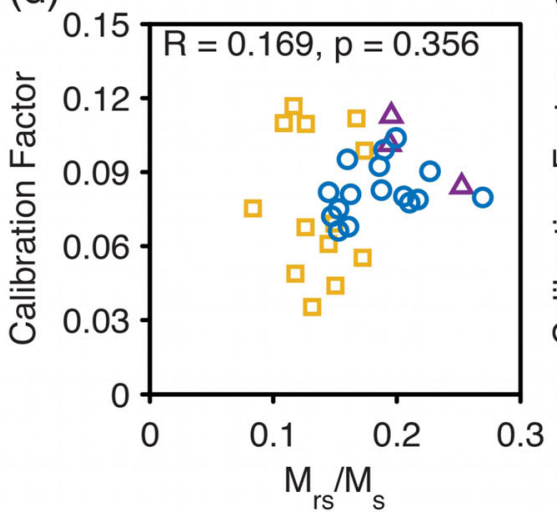

(b)

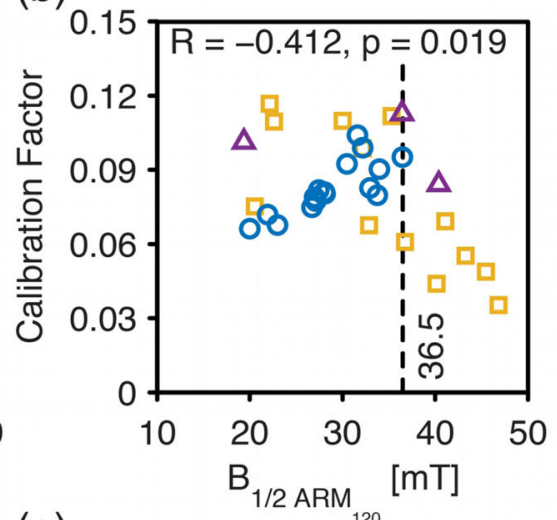

(e)

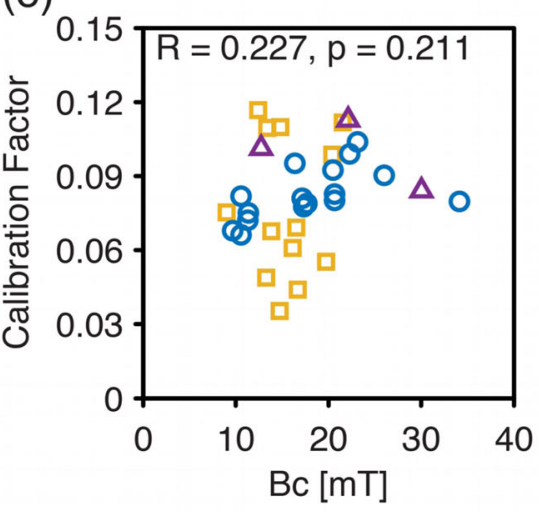

(c)

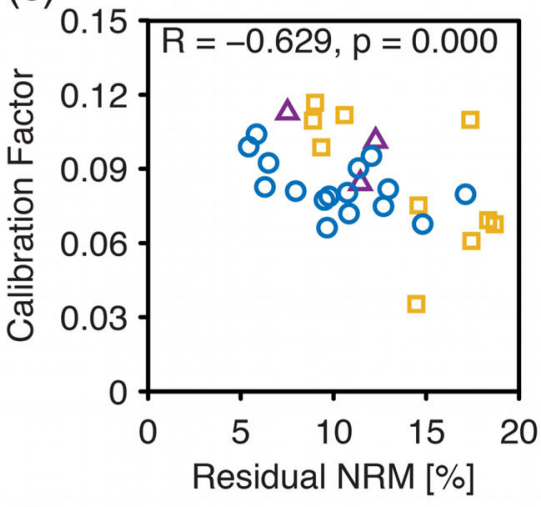

(f)

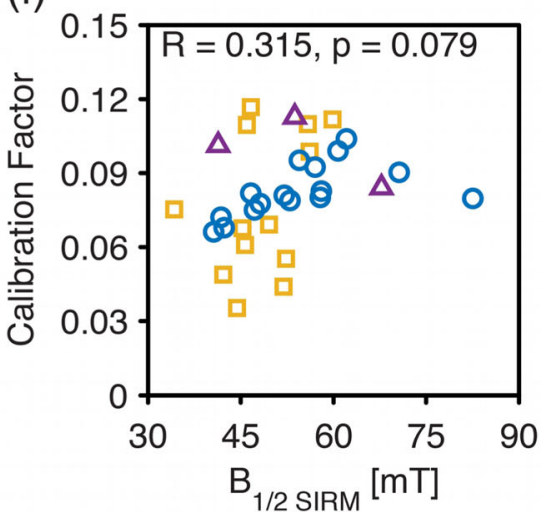

Figure 6. Accepted specimen calibration factors as a function of (a) the $\mathrm{ARM}_{120} \mathrm{MDF}$, (b) $B_{1 / 2} \mathrm{ARM} 120$, (c) $B_{1 / 2} \mathrm{SIRM}$, (d) $M_{\mathrm{rS}} / M_{\mathrm{S}}$ (squareness), (e) coercivity $\left(B_{\mathrm{c}}\right)$, and (f) the mean residual NRM after demagnetization to $120 \mathrm{mT}$ (as a percentage of the original NRM). The dashed lines in parts (a) and (b) represent possible thresholds for rock magnetic selection. All other symbols are the same as in Fig. 5.

$\leq 37.2 \mathrm{mT}$ screened calibration $(0.0857 \pm 0.0178)$, however, the palaeointensity estimates are systematically lower than the expected field (Figs 7c and d). For the selected data, this corresponds to a deviation of mean of -0.056 and for the unselected data -0.156 : underestimates of $\sim 5$ per cent and $\sim 14$ per cent, respectively.

It should be noted that, if the $B_{1 / 2 \mathrm{ARM} 120} \leq 36.5 \mathrm{mT}$ threshold is used, the mean calibration factor increases, which further increases the underestimation of the rock magnetic selected calibration. Although the systematic underestimation from our rock magnetically selected calibrations is small, for this particular data set, we find no compelling reason to support the use of a rock magnetic selection statistic. This is likely due to the preferential rejection of non-ideal data through the stricter selection process applied in deriving our calibration.

We cannot, however, exclude the possibility that further rock magnetic investigation or restriction of material types may lead a better constrained calibration. However, given the wide range of variability of TRM/ARM across the SD size range, the range that is traditional viewed as being ideal for palaeointensity determinations, it is difficult to assess what is an appropriate target value for the calibration of the pseudo-Thellier method, other than the range of values expected for SD grains, which our data are comparable to.

Due to the strong dependence on grain size, ARM based palaeointensity methods are often viewed as order-of-magnitude methods (cf. Fig. 4). Using our preferred calibration, 95 per cent of de Groot et al.'s unselected results are all within a factor of 4 of the known field. For the selected results, 95 per cent are within a factor of 1.3 (deviations of \pm 0.26 ) and all are within a factor of 1.7 (deviations of $\pm 0.53)$. This suggests that the pseudo-Thellier method is accurate to within a factor 4 , but may be much more accurate with careful data analysis and selection.

\subsubsection{Comparison to thermal based palaeointensity methods}

Both de Groot et al. (2015) and de Groot et al. (2016) attempted to refine the pseudo-Thellier calibration by cross-calibrating to thermal based methods. As we have noted previously, although useful as a cross-validation tool, this approach is not a true calibration of the pseudo-Thellier method. In Fig. 7(e), we plot our new calibration alongside the original and the data of de Groot et al. (2015) and de Groot et al. (2016). Although the data close to the original calibration, all are approximately within our one standard deviation envelope. When accounting for the uncertainty of both the calibration and the thermal palaeointensity estimates themselves, our newly calibrated pseudo-Thellier method yields results that are consistent with traditional thermal-based palaeointensity methods.

\subsection{The uncertainty of pseudo-Thellier estimates}

Our new data set provides a new measure of the uncertainty associated with the calibration of the pseudo-Thellier method $(0.0820 \pm 0.0207)$. This uncertainty, however, must be correctly propagated into the final a palaeointensity estimate. An average pseudo-Thellier palaeointensity estimate $\left(m_{\mathrm{B}}\right)$ is given by $m_{B}=\frac{m_{s}}{c}$, 
(a)

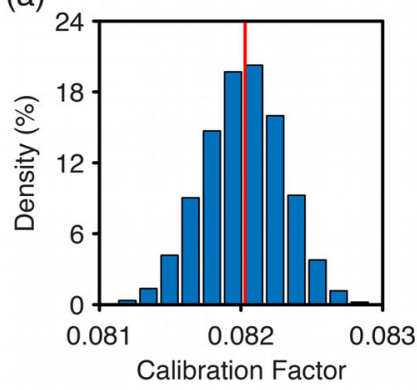

(b)

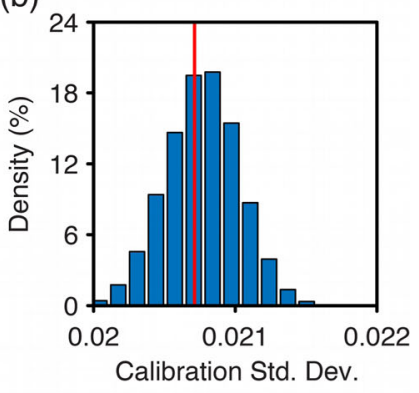

(c)

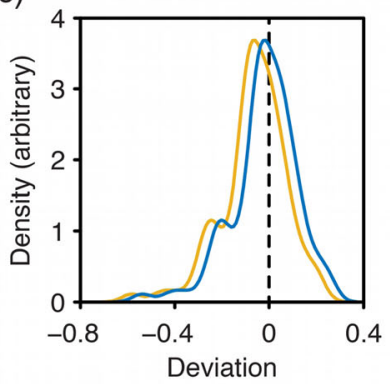

(e)

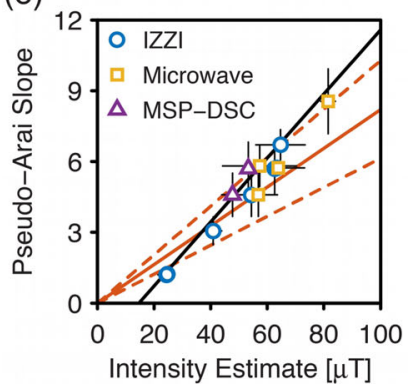

(d)

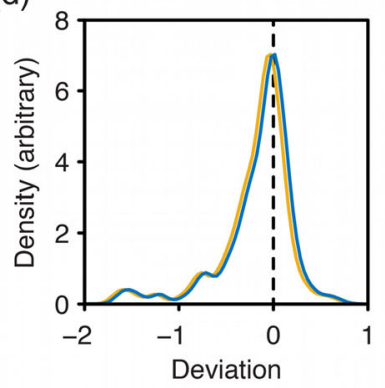

As an example, we consider the $1090 \mathrm{AD}$ data from Hawaii, which record a relatively high palaeointensity $(63.5 \pm 1.8 \mu \mathrm{T}$; de Groot et al. 2013). Using the preferred data from (de Groot et al. 2013) the mean pseudo-Thellier slope is $6.631 \pm 0.247$ ( \pm 3.7 per cent). With our new calibration the mean intensity is $80.7 \mu \mathrm{T}$, which is higher than previously estimated. The uncertainty on this estimate, however, is much larger $\pm 20.6 \mu \mathrm{T}$ ( \pm 25.5 per cent) and is dominated by the inherent variability in the calibration factor.

\subsection{Implications for previous results}

Although a relatively new method, a considerable number of results have already been obtained using the pseudo-Thellier method (de Groot et al. 2013, 2014, 2015, 2016). In comparison to previous calibrations, our new calibration indicates that low palaeointensity estimates will be systematically overestimated and that high palaeointensity estimates will be underestimated (e.g. the $1090 \mathrm{AD}$ data above), but in all cases, the uncertainty will be higher.

de Groot et al. (2015) produced a number of new data from the Canary Islands, which were contemporaneously studied by Kissel et al. (2015) who verified and contested some results. In particular, the Montaña Reventada lava flow yielded discordant results between de Groot et al. (2015) and Kissel et al. (2015), who obtained $81.7 \pm 8.7 \mu \mathrm{T}$ and $57.9 \pm 6.4 \mu \mathrm{T}$, respectively. The result of de Groot et al. (2015) comes from both pseudo-Thellier and microwave Thellier data, but the pseudo-Thellier average from 6 results is $81.7 \pm 10.9 \mu \mathrm{T}$. With our new calibration and uncertainty, this becomes $104.3 \pm 31.2 \mu \mathrm{T}$. Although the intensity value has been shifted higher, due to the increased uncertainty, it is still consistent with de Groot et al.'s microwave results $(81.6 \pm 2.6 \mu \mathrm{T}$, $N=3$ ) and within less than 1.5 standard deviations of the result of Kissel et al. (2015). Although the increase in the error of the pseudo-Thellier estimation does not fully reconcile the differences from these two studies, it illustrates the importance of correctly assessing the uncertainty associated with pseudo-Thellier results. It should be noted that physical sampling strategy has also been suggested as an important factor for why these two studies differ (Kissel et al. 2015).

de Groot et al. (2015) also note that one of their sites, TF-1909, records a pseudo-Thellier palaeointensity estimate that is low (22.0 $\mu \mathrm{T}$ ) with respect to the expected IGRF value of $\sim 40 \mu \mathrm{T}$. Using their selected data and our calibration we estimate a value of $12.1 \pm 4.0$ $\mu \mathrm{T}$, which is much lower than the expected value. We cannot reconcile this discrepancy and, following with de Groot et al. (2015), we call upon some, as yet unknown, rock magnetic behaviour to explain this unusually low value. We also note that employing our data selection procedures may yield a different result, but this remains untested. In the absence of such an analysis, however, this result implies that the pseudo-Thellier method may only be accurate to within a factor of $\sim 4$.

The examples explored here illustrate the need for a more complete reassessment of the previously published pseudo-Thellier results and, due to the larger uncertainty associated with these results, effort should be made to cross-validate pseudo-Thellier palaeointensities with results from other methods. We also recommend that all future pseudo-Thellier analyses should be combined with comprehensive rock magnetic analyses, which might reveal more useful rock magnetic screening methods not identified here. Given the sensitivity of magnetometers, which allows measurement of small specimens, and the non-destructive nature of the pseudo-Thellier 
method, we recommend that such rock magnetic analyses be performed on the same specimen, as was done here.

\subsection{Application to extraterrestrial materials}

One of the primary uses of non-heating palaeointensity methods is the study of extraterrestrial materials, which can be extremely sensitive to laboratory heating. Although palaeointensity methods based on SIRM (e.g. Gattacceca \& Rochette 2004) are more common in the study of extraterrestrial materials, recently, ARM methods have become more popular (e.g. Garrick-Bethell et al. 2009; Lappe et al. 2013; Fu et al. 2014).

Our calibration is applicable to pseudo-Thellier experiments using a $40 \mu \mathrm{T}$ DC bias field during ARM acquisition, but for comparison with calibrations derived from studies focusing on extraterrestrial materials it needs to be generalized for any bias field. By multiplying out the calibration factor $\left(c_{40}=0.0820 \pm 0.0207\right)$ by the ARM bias field $(40 \mu \mathrm{T})$ we obtain a field generalized calibration of $3.280 \pm 0.828$, such that $B_{\text {Anc }}(\mu \mathrm{T})=B_{\mathrm{ARM}}(\mu \mathrm{T}) \times\left|b_{\mathrm{PA}}\right| /$ 3.280. This value of 3.280 is slightly higher than that obtained by $\mathrm{Yu}$ (2010), but it is still consistent with his value of $2.60 \pm 1.32$ derived from thermally stabilized gabbro specimens. Our value, however, is much higher than that of Lappe et al. (2013), who obtained values of $0.7-1.85$ for natural and synthetic dusty olivine, which may have a more complicated mineralogy than the specimens used in our study. In addition, Lappe et al.'s experiments used TRM bias fields of 200-1500 $\mu \mathrm{T}$ and ARM bias fields of $20-400 \mu \mathrm{T}$. Therefore, the effects of nonlinear remanence acquisition in large fields may be significant.

In both of these studies, and when using ARM based methods on extraterrestrial materials in general, comparison of ARM acquisition and demagnetization spectra ( $c f$. Fig. 1f) is rarely performed (Garrick-Bethell et al. 2009; Yu 2010; Lappe et al. 2013). Our analysis further demonstrates that the coercivity spectra of TRM can be notably different from that of ARM (e.g. Fig. 1a), but also that ARM demagnetization spectra can be different from ARM acquisition spectra (e.g. Fig. 1f). The requirement of reciprocity, where remanences activate the same blocking spectra, whether it is blocking temperature or coercivity, is a fundamental premise of all palaeointensity studies that should be tested. The selection process that we introduce here allows for this and we recommend the same, or similar selection procedures be adopted for all ARM based palaeointensity methods.

By utilizing our selection criteria it is possible to use the pseudoThellier method to obtain results that are within a factor 4 ( $c f$. the discussion of site TF-1909 in Section 4.6) or better ( $c f$. the Hawaiian palaeointensity estimates in Figs 7c and d). This makes the accuracy of ARM methods comparable to the suggested accuracy of SIRM based methods (Gattacceca \& Rochette 2004). However, to be able to better generalize the pseudo-Thellier method a more extensive data set that covers materials relevant to extraterrestrial specimens combined with a detailed exploration of ARM bias field dependence and nonlinear remanence acquisition are needed.

\section{CONCLUSIONS}

We have re-estimated the calibration of the pseudo-Thellier method using a collection 56 well-characterized specimens that represent a wide range of volcanic materials used for obtaining absolute palaeointensity estimates. Following careful data selection that tests fundamental assumptions about palaeointensity behaviour, 32 spec- imens are deemed as acceptable and yield calibration behaviour that is consistent with a zero intercept term (i.e. a specimen with zero NRM should have a pseudo-Arai slope of zero), which is a theoretical expectation that had not been met by some previous calibrations. Our final calibration factor $(0.0820 \pm 0.0207)$ exhibits variability that is consistent with other estimates and falls within the range of variability expected from SD magnetite. This calibration is applicable to pseudo-Thellier experiments using a $40 \mu \mathrm{T}$ DC bias field during ARM acquisition, but can be generalized for any bias field $(3.280 \pm 0.828)$. Future studies, however, need to systematically explore the influence of ARM bias field to verify this calibration of the pseudo-Thellier method. Similarly, other important factors such as ARM anisotropy and the influence of AF decay rates need to be better quantified.

A systematic rock magnetic investigation reveals that, without data selection, there is a strong correlation between high-field rock magnetic behaviour and the calibration factors obtained from individual specimens. However, following data selection, we observe that the calibration factors are no longer correlated with high-field rock magnetic properties, but are correlated with weak-field parameters. This suggests that the pseudo-Thellier calibration factors are dominated by domain state variations in highly magnetic minerals (i.e. grain size and/or magnetic interactions in magnetite and/or maghemite). However, by using a new set of selection criteria (Table 1), we are able to effectively screen out much of this variation. The calibration factors remaining after applying these criteria are correlated with low-field remanence properties, which may be related to subtle variations in magnetic mineralogy of these particular specimens. Nevertheless, such subtle variations are difficult to distinguish from subtle grain size variations over a very narrow range (e.g. Fig. 3). Further study on a larger data set with a wider range of mineralogical variations may aid in identifying the effect of such subtleties.

Despite a differing approach to data selection and different ARM and AF equipment, our new calibration yields highly accurate results when applied to the independent data set of de Groot et al. (2013), which serves as demonstration of the veracity of our calibration. It is also consistent with results from more traditional thermal based palaeointensity methods and illustrates that the pseudo-Thellier method is a useful and valuable tool for obtaining absolute palaeointensity estimates. However, pseudo-Thellier results carry with them an inherent uncertainty associated with the calibration factor, which stems from the strong dependence of ARM on magnetic grain size. This uncertainty is at least 25 per cent and is larger than most thermal based palaeointensity methods.

An analysis of data from historical lavas suggests that the pseudoThellier method is accurate to within a factor of 4 , but with careful data selection this may be reduced to a factor of 2 . The pseudoThellier method, as applied here, may therefore have important applications in obtaining palaeointensities from extraterrestrial materials. Nevertheless, because of large uncertainties, the pseudoThellier method should be used to complement and cross-validate results from other methods and should only be used as a standalone method in cases where other methods fail or where non-destructive treatment is required.

\section{ACKNOWLEDGEMENTS}

GAP acknowledges funding from NSFC grants 41374072 and 41574063. DH acknowledges support from Australian Research Council grant DP160100805. YP and GAP acknowledges 
support from CAS project XDB18010203. We thank Huafeng Qin for his assistance. We also thank reviewers Roger Fu and Yongjae $\mathrm{Yu}$ for their useful suggestions. Data generated in this work will be made publicly available through the MagIC database (earthref.org/MagIC/) following completion of ongoing work. Direct data requests are welcome.

\section{REFERENCES}

Coe, R.S., Grommé, S. \& Mankinen, E.A., 1978. Geomagnetic paleointensities from radiocarbon-dated lava flows on Hawaii and the question of the Pacific nondipole low, J. geophys. Res., 83, 1740-1756.

de Groot, L.V., Biggin, A.J., Dekkers, M.J., Langereis, C.G. \& HerreroBervera, E., 2013. Rapid regional perturbations to the recent global geomagnetic decay revealed by a new Hawaiian record, Nat. Commun., 4, doi:10.1038/ncomms3727.

de Groot, L.V., Dekkers, M.J., Visscher, M. \& ter Maat, G.W., 2014. Magnetic properties and paleointensities as function of depth in a Hawaiian lava flow, Geochem. Geophys. Geosyst., 15, 1096-1112.

de Groot, L.V. et al., 2015. High paleointensities for the Canary Islands constrain the Levant geomagnetic high, Earth planet. Sci. Lett., 419, 154-167.

de Groot, L.V., Pimentel, A. \& Di Chiara, A., 2016. The multi-method paleointensity approach applied to volcanics from Terceira: full-vector geomagnetic data for the past $50 \mathrm{kyr}$, Geophys. J. Int., 206(1), 590-604.

Dekkers, M.J. \& Böhnel, H.N., 2006. Reliable absolute palaeointensities independent of magnetic domain state, Earth planet. Sci. Lett., 248, 508517.

Dunlop, D.J. \& Argyle, K.S., 1997. Thermoremanence, anhysteretic remanence and susceptibility of submicron magnetites: nonlinear field dependence and variation with grain size, J. geophys. Res., 102, 20 199-20 210.

Dunlop, D.J. \& West, G.F., 1969. An experimental evaluation of single domain theories, Rev. Geophys., 7, 709-757.

Dunlop, D.J., Bailey, M.E. \& Westcott-Lewis, M.F., 1975. Lunar paleointensity determinations using anhysteretic remanence (ARM): a critique, in Proc. Lunar Sci. Conf. 6th, Pergamon Press, Inc., Houston, TX, pp. 3063-3069.

Fabian, K., 2006. Approach to saturation analysis of hysteresis measurements in rock magnetism and evidence for stress dominated magnetic anisotropy in young mid-ocean ridge basalt, Phys. Earth planet. Inter., 154, 299-307.

Fabian, K. \& Leonhardt, R., 2010. Multiple-specimen absolute paleointensity determination: an optimal protocol including pTRM normalization, domain-state correction, and alteration test, Earth planet. Sci. Lett., 297, 84-94.

Fu, R.R. et al., 2014. Solar nebula magnetic fields recorded in the Semarkona meteorite, Science, 346, 1089-1092.

Garrick-Bethell, I., Weiss, B.P., Shuster, D.L. \& Buz, J., 2009. Early Lunar Magnetism, Science, 323, 356-359.

Gattacceca, J. \& Rochette, P., 2004. Toward a robust normalized magnetic paleointensity method applied to meteorites, Earth planet. Sci. Lett., 227, 377-393.

Gillingham, D.E.W. \& Stacey, F.D., 1971. Anhysteretic remanent magnetization (ARM) in magnetite grains, Pure appl. Geophys., 91, 160-165.

Hartstra, R.L., 1983. TRM, ARM and Isr of two natural magnetites of MD and PSD grain size, Geophys. J. R. astr. Soc., 73, 719-737.

Jackson, M. \& Solheid, P., 2010. On the quantitative analysis and evaluation of magnetic hysteresis data, Geochem. Geophys. Geosyst., 11, Q04Z15, doi:10.1029/2009GC002932.

Kissel, C., Laj, C., Rodriguez-Gonzalez, A., Perez-Torrado, F., Carracedo, J.C. \& Wandres, C., 2015. Holocene geomagnetic field intensity variations: contribution from the low latitude Canary Islands site, Earth planet. Sci. Lett., 430, 178-190.
Lappe, S.-C.L.L., Feinberg, J.M., Muxworthy, A. \& Harrison, R.J., 2013. Comparison and calibration of nonheating paleointensity methods: a case study using dusty olivine, Geochem. Geophys. Geosyst., 14, 2143-2158.

Levi, S., 1977. Effect of magnetite particle size on paleointensity determinations of the geomagnetic field, Phys. Earth planet. Inter, 13, 245-259.

Levi, S. \& Merrill, R.T., 1976. A comparison of ARM and TRM in magnetite, Earth planet. Sci. Lett., 32, 171-184.

Mullender, T.A.T., Frederichs, T., Hilgenfeldt, C., de Groot, L.V., Fabian, K. \& Dekkers, M.J., 2016. Automated paleomagnetic and rock magnetic data acquisition with an in-line horizontal " $2 \mathrm{G}$ " system, Geochem. Geophys. Geosyst., 17, doi:10.1002/2016GC006436.

Muxworthy, A.R. \& Heslop, D., 2011. A Preisach method for estimating absolute paleofield intensity under the constraint of using only isothermal measurements: 1. Theoretical framework, J. geophys. Res., 116, B04102, doi:10.1029/2010JB007843.

Muxworthy, A.R., Heslop, D., Paterson, G.A. \& Michalk, D., 2011. A Preisach method for estimating absolute paleofield intensity under the constraint of using only isothermal measurements: 2. Experimental testing, J. geophys. Res., 116, B04103, doi:10.1029/2010jb007844.

Nagata, T., Arai, Y. \& Momose, K., 1963. Secular variation of the geomagnetic total force during the last 5000 years, J. geophys. Res., 68, 5277-5281.

Paterson, G.A., 2011. A simple test for the presence of multidomain behaviour during paleointensity experiments, J. geophys. Res., 116, B10104, doi:10.1029/2011JB008369.

Paterson, G.A., Muxworthy, A.R., Roberts, A.P. \& Mac Niocaill, C., 2010a. Assessment of the usefulness of lithic clasts from pyroclastic deposits for paleointensity determination, J. geophys. Res., 115, B03104, doi:10.1029/2009JB006475.

Paterson, G.A., Roberts, A.P., Muxworthy, A.R., Mac Niocaill, C., Gurioli, L., Viramonté, J.G., Navarro, C. \& Weider, S., 2010b. Paleomagnetic determination of emplacement temperatures of pyroclastic deposits: an under-utilized tool, Bull. Volcanol., 72, 309-330.

Paterson, G.A., Tauxe, L., Biggin, A.J., Shaar, R. \& Jonestrask, L.C., 2014. On improving the selection of Thellier-type paleointensity data, Geochem. Geophys. Geosyst., 15, 1180-1192.

Paterson, G.A., Biggin, A.J., Hodgson, E. \& Hill, M.J., 2015. Thellier-type paleointensity data from multidomain specimens, Phys. Earth planet. Inter, 245, 117-133.

Rahman, A.A., Duncan, A.D. \& Parry, L.G., 1973. Magnetization of multidomain magnetite particles, Riv. Ital. Geofis., 22, 259-266.

Stephenson, A. \& Collinson, D.W., 1974. Lunar magnetic field palaeointensities determined by an anhysteretic remanent magnetization method, Earth planet. Sci. Lett., 23, 220-228.

Tauxe, L. \& Staudigel, H., 2004. Strength of the geomagnetic field in the Cretaceous Normal Superchron: new data from submarine basaltic glass of the Troodos Ophiolite, Geochem. Geophys. Geosyst., 5, Q02H06, doi: $10.1029 / 2003 \mathrm{GC} 000635$

Thellier, E. \& Thellier, O., 1959. Sur l'intensité du champ magnétique terrestre dans le passé historique et géologique, Ann. Geophys., 15, 285-376.

Walton, D., Snape, S., Rolph, T.C., Shaw, J. \& Share, J., 1996. Application of ferrimagnetic resonance heating to palaeointensity determinations, Phys. Earth planet. Inter., 94, 183-186.

Yu, Y., 2010. Paleointensity determination using anhysteretic remanence and saturation isothermal remanence, Geochem. Geophys. Geosyst., 11, Q02Z12, doi:10.1029/2009GC002804.

Yu, Y., Dunlop, D.J. \& Özdemir, Ö., 2002. Partial anhysteretic remanent magnetization in magnetite 2. Reciprocity, J. geophys. Res., 107, EPM 8-1-EPM 8-9, doi:10.1029/2001JB001269.

Yu, Y., Dunlop, D.J. \& Özdemir, Ö., 2003. Are ARM and TRM analogs? Thellier analysis of ARM and pseudo-Thellier analysis of TRM, Earth planet. Sci. Lett., 205, 325-336. 


\section{SUPPORTING INFORMATION}

Additional Supporting Information may be found in the online version of this paper:

Figure S1. Comparison of hysteresis (a) coercivity ratio and (b) squareness before and after heating. Data before heating are from sister specimens from Paterson et al. (2010b) and unpublished Emeishan basalt data. We note that specimen heterogeneity may cause some of the differences. (c) Day plot comparison of our heated specimens (coloured symbols) and unheated natural volcanic materials (black dots). In all plots, the blue circles are the Emeishan specimens (groups A and C), the yellow squares are the Mt. St. Helens specimens (group D) and the purple triangles are the Vesuvius specimens (group L). In parts (a) and (b) the dashed lines and 1-to-1 ratio lines. The unheated natural volcanic hysteresis data in part (c) are sourced from Paterson et al. (2010b) and Muxworthy et al. (2011) and include lava flows and pyroclastic lithic clasts from seven localities.
Table S1. Mean selected pseudo-Arai slopes ( \pm one standard deviation) from the used specimens in the four different NRM fields.

Table S2. The accepted specimens and their mean calibration factors and rock magnetic properties. ARM120 MDF, $B_{1 / 2}$ ARM 120 and Residual NRM are calculated as the averages values from the selected field experiments.

Table S3. Pseudo-Arai and ARM-ARM plot curvature from the data of Yu et al. (2003). Curvature is calculated from all data points. Data were digitized from Yu et al. (2003) and the entire plot curvature was calculated following Paterson (2011).

(http://gji.oxfordjournals.org/lookup/suppl/doi:10.1093/gji/ ggw349/-/DC1)

Please note: Oxford University Press is not responsible for the content or functionality of any supporting materials supplied by the authors. Any queries (other than missing material) should be directed to the corresponding author for the paper. 